\title{
Anticipating land-use impacts of self-driving vehicles in the Austin, Texas, region
}

\author{
Tyler Wellik \\ University of Texas \\ tywellik@utexas.edu
}

\author{
Kara Kockelman \\ University of Texas \\ kkockelm@mail.utexas.edu
}

\begin{abstract}
This paper used an implementation of the land-use model SILO in Austin, Texas, over a 27-year period with an aim to understand the impacts of the full adoption of self-driving vehicles on the region's residential land use. SILO was integrated with MATSim for the Austin region. Land-use and travel results were generated for a business-asusual case (BAU) of $0 \%$ self-driving or "autonomous" vehicles (AVs) over the model timeframe versus a scenario in which households' value of travel time savings (VTTS) was reduced by $50 \%$ to reflect the travelburden reductions of no longer having to drive. A third scenario was also compared and examined against BAU to understand the impacts of rising vehicle occupancy (VO) and/or higher roadway capacities due to dynamic ride-sharing (DRS) options in shared AV (SAV) fleets. Results suggested an $8.1 \%$ increase in average work-trip times when VTTS fell by $50 \%$ and VO remained unaffected (the $100 \%$ AV scenario) and a $33.3 \%$ increase in the number of households with "extreme work-trips" (over 1 hour, each way) in the final model year (versus BAU of $0 \% \mathrm{AVs}$ ). When VO was raised to 2.0 and VTTS fell instead by 25\% (the "HiDRS" SAV scenario), average work-trip times increased by $3.5 \%$ and the number of households with "extreme work-trips" increased by $16.4 \%$ in the final model year (versus BAU of $0 \% \mathrm{AVs}$ ). The model also predicted $5.3 \%$ fewer households and $19.1 \%$ more available, developable land in the city of Austin in the $100 \%$ AV scenario in the final model year relative to the BAU scenario's final year, with $5.6 \%$ more households and $10.2 \%$ less developable land outside the city. In addition, the model results predicted $5.6 \%$ fewer households and $62.9 \%$ more available developable land in the city of Austin in the Hi-DRS SAV scenario in the final model year relative to the BAU scenario's final year, with $6.2 \%$ more households and $9.9 \%$ less developable land outside the city.
\end{abstract}

Keywords: Self-driving, automated, or autonomous vehicles; land use; integrated transportation land-use modeling; urban sprawl; agent-based simulation

\section{Article history:}

Received: December 31, 2019

Received in revised form:

March 19, 2020

Accepted: March 25, 2020

Available online: August 4, 2020

Copyright 2020 Tyler Wellik \& Kara Kockelman

http://dx.doi.org/10.5198/jtlu.2020.1717

ISSN: $1938-7849$ | Licensed under the Creative Commons Attribution - Noncommercial License 4.0

The Journal of Transport and Land Use is the official journal of the World Society for Transport and Land Use (WSTLUR) and is published and sponsored by the University of Minnesota Center for Transportation Studies. 


\section{$1 \quad$ Introduction and motivation}

American cities have formed and transformed contemporaneously with transportation technologies. The suburbanization, or urban sprawl, of U.S. cities can be mainly attributed to cars and highway infrastructure. Muller (2017) has shown that in American cities, through time, the built-up urban area has maintained a rather constant 45-minute time-radius from the center. Each transportation technology has made travel easier and has therefore extended the distance of this time-radius, allowing for cheaper suburban residential areas to be unlocked. From walking horsecars in the nineteenth century to electric streetcars in the early twentieth century to the mainstream adoption of automobiles and the build-out of freeways in the mid-twentieth century, major expansions of cities have been a by-product (Muller, 2017).

A new era of urban centralization is beginning as planners find that building more freeways is either not a solution or not an option (Muller, 2017). Transportation technologies are also changing faster than ever before (Dowling \& Morgan, 2019). In contrast to this era of centralization, self-driving "autonomous" vehicle (AV) technology is on the horizon, which is certain to alter cities and regions significantly (Muller, 2017). Transportation economists remark that travelers would prefer to pay less for their travel and, if they can get it for less, they will tend to travel more. These new transportation technologies, namely AVs, have the opportunity to reduce the time cost of travel compared to other travel modes because they remove the burden of driving, allowing productive time to be spent in one's vehicle. Thus, any change in transportation technology that affects travel costs will also impact land use, and changes in land use impacts travel patterns, creating a cycle of change (Dowling \& Morgan, 2019). For example, it has been shown that households will tend to move to more distant regions when they have access to AVs, which has impacts on travel and land-use behavior (Huang, Kockelman, \& Quarles, 2019).

The advent of $\mathrm{AVs}$ makes for an interesting new transportation era because of the relatively long lead time to plan and prepare for the technology before it is expected to become widely implemented. Note that the Society of Automotive Engineers defines five levels of automation. These levels range from minor driver assistance features such as cruise control at Level 1, to fully self-driving vehicles at Level 5 (SAE International, 2018). In this study, when the term AV is used, the reference is to Level 4, where the vehicle is fully self-driving, but it must remain on the road infrastructure. Driverless testing on public roads has begun in many U.S. states and many nations for major players such as Google's Waymo and GM Cruise Automation (National Conference of State Legislatures, 2019). If these major players are able to reduce travel costs significantly below $\$ 1 /$ mile, there is expected to be a major adoption of $A V s$ by the greater public. A recent stated-preference survey indicated that Americans' average willingness to pay for use of SAVs is $\$ 0.44 /$ mile (Quarles \& Kockelman, 2019). In contrast, the average cost of sedan ownership in the U.S. is $\$ 0.59 /$ mile (Edmonds, 2017). This adoption would significantly impact travelers' value of travel time savings (VTTS). This is expected to increase the distance many are willing to travel, as well as have other land-use impacts, such as a decreased need for parking facilities (Dowling \& Morgan, 2019). Engineers, planners, and policymakers alike can use this time to ensure a successful implementation by making use of models to understand land use, energy, and transportation implications, allowing them to assess the role of policy and its impacts on these attributes.

The interaction between transportation and land-use patterns are important and reinforcing. According to Hawkins and Habib (2018), the use of integrated transport and land-use models (ITLUMs) is crucial to understanding and evaluating the impacts of the implementation of AVs on transportation demand, transportation supply, and residential development. Most studies expect AVs to increase urban sprawl because of more efficient driving and lower VTTS associated with removing the burden of driving. Modeling these impacts for the six-county Austin, Texas, metropolitan region (hereby referred 
to as simply the Austin Metro) is the focus of this section, but it is important to note that there are conflicting expectations on the relationship that $\mathrm{AVs}$ will have for urban land use. Some have claimed that shared AV fleets (SAVs) have the possibility to re-urbanize cities because parking will no longer be a necessary dwelling consideration, making more central, downtown areas more desirable (Hawkins \& Habib, 2018). A limitation of the present study is that these effects are not considered. Interestingly, one recent study showed that $10 \%$ of survey recipients who were likely to move in the next few years said the availability of AVs and SAVs would mean that they would be likely to move further from the city center and $15 \%$ of survey recipients indicated that the availability of AVs and SAVs would mean that they would likely move closer to the city center (Quarles \& Kockelman, 2019). So, this study limitation is a significant one.

More recent ITLUMs have focused on agent-based microsimulation modeling techniques, in contrast to traditional gravity models or econometric models. SILO (Simple Integrated LandUse Orchestrator) was the chosen microsimulation land-use model (LUM) because of its relative simplicity (compared to other microsimulation LUMs), leading to reasonably short run times, lowered data requirements, and its ease of integration with the well-established agent-based microsimulation transportation model MATSim (Hawkins \& Habib, 2018).

\section{$2 \quad$ Literature review}

Transportation and land-use development are in a constant feedback cycle; each informs the other and when one alters, the other adjusts, and vice versa. Because of this relationship, ITLUMs improve the reasonability of model results compared to stand-alone transport models. ITLUMs are not new, but there has been a new wave of interest in them because of upcoming transportation trends and technologies, such as AVs, that are expected to significantly impact land use (Dowling \& Morgan, 2019). The most common concern in using an ITLUM is the intensity of data needs, which is one reason why SILO was chosen for this study. SILO integrated with MATSim is less data-intensive relative to similar ITLUMs (Moeckel, 2018a).

SILO is a simplified microsimulation model with a focus on time and budget constraints as opposed to utility maximization (Moeckel, 2019a). There is a trend towards microsimulation in LUMs and in travel demand models (TDMs). Benefits of microsimulation include that it is more flexible to a higher level of population detail, and the model is easier to explain because agents are modeled explicitly, and true decision-making is modeled more closely. These benefits come with the limitations of longer run times as well as variations in the same model runs because of the stochastic nature of the model (Moeckel, 2018a). SILO is simplified in its methodology, which decreases its data requirements and its run times. In contrast to many LUMs, SILO does not assume agents are always fully knowledgeable in making decisions (for example, they will not know information on all of the vacant dwellings in the region when looking to move). Rather than maximizing utility, agents look to satisfy requirements, within time and money constraints, that may be biased or based in habit. Further, SILO has also been integrated with MATSim in previous studies, making it a good choice of ITLUM for our needs (Hawkins \& Habib, 2018).

The integration of SILO and MATSim was first published in 2016 for the Maryland study region. Because SILO and MATSim are both written in Java, integration was reported to be relatively seamless (Ziemke, Nagel, \& Moeckel, 2016). In addition, both models are microsimulation agent-based models, so a fully agent-oriented ITLUM was proven and reasonable results were found through this methodol-

ogy. Congestion levels and patterns were simulated well, even though MATSim was created based on OpenStreetMaps (OSM) data that were never altered or calibrated (Ziemke et al., 2016). 
This study looks to identify land-use impacts of AVs using the ITLUM of SILO and MATSim, and so similar research in this realm was reviewed. Of note is a study on congestion and accessibility impacts of AVs by Cohen and Cavoli (2019). They looked at traffic flow and accessibility implications for a range of government intervention (or non-intervention) scenarios. Using surveys and extensive literature reviews, the authors supported what many had hypothesized: that if the free market is left alone to deal with the adoption of $A V s$, we are likely to see a scenario that does not maximize social welfare. The authors looked at various categories of policy intervention, including land-use policies such as zoning, regulation policies such as banning the empty running of $\mathrm{AVs}$, and infrastructure policies such as adding walking or biking paths. They looked at nineteen interventions and determined the corresponding implications for traffic flow and accessibility, but they did not reach a final conclusion on what combination of government interventions serve the best chance at mitigating negative impacts of AV penetration (Cohen \& Cavoli, 2019).

It is also important to review literature that looks at the land use-transport relationship as it pertains to AVs. A paper by Soteropoulos, Berger, and Ciari (2019) reviewed modeling studies that looked at impacts of AVs on travel behavior and land use. The authors looked at studies between 2013 and 2018 that contained keywords of AVs, transport, land use, and modeling. Most of the studies cited examined travel behavior implications of AVs, though several examined land-use impacts, mainly through the use of ITLUMs. Studies varied in whether they investigated full replacement of vehicles or a small share of vehicle trips that were modeled in an AV. A common assumption is the reduction of VTTS in AVs due to an increased productivity or comfort. Increases in roadway capacity due to AVs is another recurring assumption made in these models. For the most part, studies used vehicle miles traveled (VMT) or vehicle hours traveled (VHT) as indicators for travel changes, and various land use impacts were analyzed, from parking needs to location choices of households and employment. Studies mostly found an increase in VMT, while VHT impacts vary based on study assumptions. In looking at the effects of AVs on households and employment, studies mostly predict that there will be an increase of population in well-connected outer regions. This is especially the case in studies with high discounts of VTTS or large increases in road capacity. It is noted that studies that examine land-use impacts of AVs generally have low spatial detail, tending to only distinguish between urban and suburban areas, for example. This is the point that this study is meant to build on, to place more weight and attention to the more complicated land-use patterns that could not be interrogated in previous models (Soteropoulos et al., 2019).

\section{$3 \quad$ Model framework}

There are three components of the modeling framework: (1) the creation of the synthetic population for the Austin Metro, (2) the LUM SILO, and (3) the transport model MATSim. The synthetic population is created before any model run begins and is updated after each model year that SILO completes. Running an LUM and a TDM each year and updating each is ideal but rarely achieved. Because of long runtimes, the TDM or LUM or both are often run for selected years only (Moeckel, 2018b). In this case, SILO is run every year and MATSim is run every tenth model year. Although running MATSim every tenth year is infrequent, it was found that this struck a balance between model runtime and the accuracy of model output. It is also supported in the literature that many ITLUMs run the transport model every ten years, including many PECAS implementations. As a specific example, the San Francisco Bay Area runs their TDM every ten years in their ITLUM implementation for the region (Moeckel, 2018b). 


\section{$4 \quad$ Synthetic population}

Before any model runs begin, the Census Public Use Micro Sample (PUMS) dataset is used to create a synthetic population for the base year, 2013 (U.S. Census Bureau, 2018). The SILO synthetic population generator, using information from the PUMS, creates a simplified microscopic representation of the actual Austin Metro population. It is simplified in that it only includes attributes deemed important to land-use modeling and it is microscopic in that every person and household is represented individually. It is not identical to the actual population of Austin, but it matches various statistical distributions of the actual population, and so it is close enough for modeling purposes (Moeckel, 2015).

The U.S. version of SILO's synthetic population generator uses the 5\% PUMS sample, which provides less household characteristic details in exchange for more spatial detail, as compared to the $1 \%$ PUMS. The spatial resolution of the 5\% PUMS are called PUMAs (Public Use Microdata Areas). Besides household details, PUMS also provides information of each person in each household and the dwellings that the households live in. PUMS includes an expansion factor which describes how many households of the true population each PUMS record represents. These expansion factors are used in SILO's synthetic population generator and they were calculated specifically to match the actual population of each PUMA (Moeckel, 2018a).

By expanding household records, we also expand synthetic persons and dwellings at the same time. Once expanded, the total number of persons and households matches the actual population of the region. In addition, the PUMS data includes information on vacant dwellings, and so this expansion should also represent a complete set of dwellings in the region, split into five different dwelling categories: single family detached (SFD), single family attached (SFA), multi-family dwellings with up to four families (MF234), multi-family dwellings with five or more families (MF5plus), and mobile homes (MHs). The PUMS data over-represented vacant dwellings by a large margin, perhaps over-representing unoccupied households when they did not respond to the surveys. The PUMS data estimated vacancy rates to be $9.8 \%$ which is much higher than most estimates that put vacancy rates around 5\% (Department of Numbers, 2017). Because of this, vacant household were randomly removed from the synthetic population until a vacancy rate of $5 \%$ was achieved.

PUMS data give dwelling locations at the PUMA level. Next, dwellings need to be allocated to model zones. Capital Area Metropolitan Planning Organization (CAMPO) zonal data was used to proportionally allocate dwellings to zones, using zonal population as a proxy for dwelling allocation. Workplace locations are disaggregated similarly; PUMS data provides work locations by PUMAs, and CAMPO zonal data was used to proportionally allocate jobs by zonal employment data (Moeckel, 2018a). In order to simulate job openings in the region, a random 5\% sample was taken of all jobs in the region, and those were duplicated but marked as available or vacant jobs.

The synthetic population generator creates four different files: one each for households, persons, dwellings, and jobs. Each person is part of a specific household and each household is matched to a certain dwelling. In addition, each working person in the synthetic population is matched with a specific job. People are assigned workplaces by drawing jobs located within their Census-specified working PUMA (Moeckel, 2018a). Note that there are also vacant jobs and dwellings that are not matched to persons or households. Extensive review of the synthetic population was completed to ensure it closely matched the Census. 


\section{Simple Integrated Land-Use Orchestrator (SILO)}

SILO is an open-source microscopic discrete choice land-use model where each person, household, and dwelling are treated as individual objects. All spatial decisions, such as household relocation or dwelling development, are modeled with logit models. Other non-spatial decisions, such as getting married or divorced, giving birth, or upgrading an existing dwelling, are modeled with Markov models by applying transition probabilities (Moeckel, 2018a). Each model year, SILO simulates many events that occur to persons, households, and dwellings. The events SILO simulates are summarized in Table 1 below. To avoid path dependency, events are modeled in random order.

Table 1. Summary of events simulated by SILO (Moeckel, 2018a)

\begin{tabular}{|l|l|l|}
\hline Household events & Person events & Dwelling events \\
\hline Household relocation & Aging & Construction of new dwellings \\
\hline Buy or sell household vehicle & Leave parental household & Renovation \\
\hline & Marriage/Divorce & Deterioration \\
\hline & Death & Demolition \\
\hline & Find a new job/ Get laid off & Increase or decrease of price \\
\hline
\end{tabular}

SILO is a simplified model with an emphasis on budget constraints as opposed to the traditional emphasis on utility maximization (Hawkins \& Habib, 2018). There are three main constraints that SILO represents. First is the housing cost constraint, representing the fact that, though housing budgets can be exceeded in the short-term, household income must harmonize with their housing budget in the long run. The second main constraint modeled in SILO is the work-trip travel time constraint, a major consideration for household location choice (Moeckel, 2015). In the Austin Metro region, the average work-trip time is 26.8 minutes, which is quite similar to the national average work-trip time of 26.4 minutes in 2017 (United States Census Bureau, 2017). When households are in the market to relocate, the job location of all workers in the household are considered, and dwellings that are far from the workers' employment locations are given a low utility. The third and final main constraint modeled in SILO is the household budget constraint. According to the Consumer Expenditure Survey from the Bureau of Labor Statistics, households spend an average of 13\% of their pre-tax income on transportation, and low-income households spend as much as $28 \%$ (U.S. Department of Labor, 2019). For more information on the inner workings of SILO, the authors recommend that readers look through Moeckel (2015).

\section{$6 \quad$ Multi-Agent Transport Simulation (MATSim)}

MATSim is an open-source, agent-based, dynamic transportation simulator that was used to track travelers across the Austin Metro region for this research (Horni, Nagel, \& Axhausen, 2016). The network for this region is obtained from OSM and converted to a network file to be used by MATSim (OpenStreetMaps, 2019). It is agent-based in that each traveler and vehicle is represented individually and seeks utility maximization. Each agent has a plan, which is a tentative itinerary for the day. Agents can improve their plan by altering activity start and end times, they can change their route, or they can change the mode they take to travel, in order to maximize their utility (Simoni, Kockelman, Gurumurthy, \& Bischoff, 2018). It uses queue-based dynamic traffic assignment as opposed to aggregated static assignment typical of traditional four-step models. Queue-based means cars on a link are in a queue that employs first-in first-out methodology, meaning it assumes one lane where vehicles cannot overtake one 
another. The link capacity varies road-to-road to account for more lanes, higher speed limits, etc. (Horni et al., 2016). Because of the high computational power needed to run this detailed agent-based simulation, five percent of the population is used to allow for reasonable run times, and then link capacities are scaled down accordingly.

Neither MATSim nor SILO generate travel demand, so in order to simply assess congestion impacts across the region, travel demand is simulated by sending all workers from home to work between the morning peak hours of 6 am to $9 \mathrm{am}$. Of course, this is a simplification that is not truly representative of the vehicles on the road, because not everyone goes to work every day; some people are sick, are on vacation, or are working from home. In addition, non-workers are found on the roads during these hours running errands or transporting their children. All things considered, it has been shown that this simulates true congestion fairly well, where congested links under this simplification replicate congested links found on Google Maps during peak travel hours (Ziemke et al., 2016).

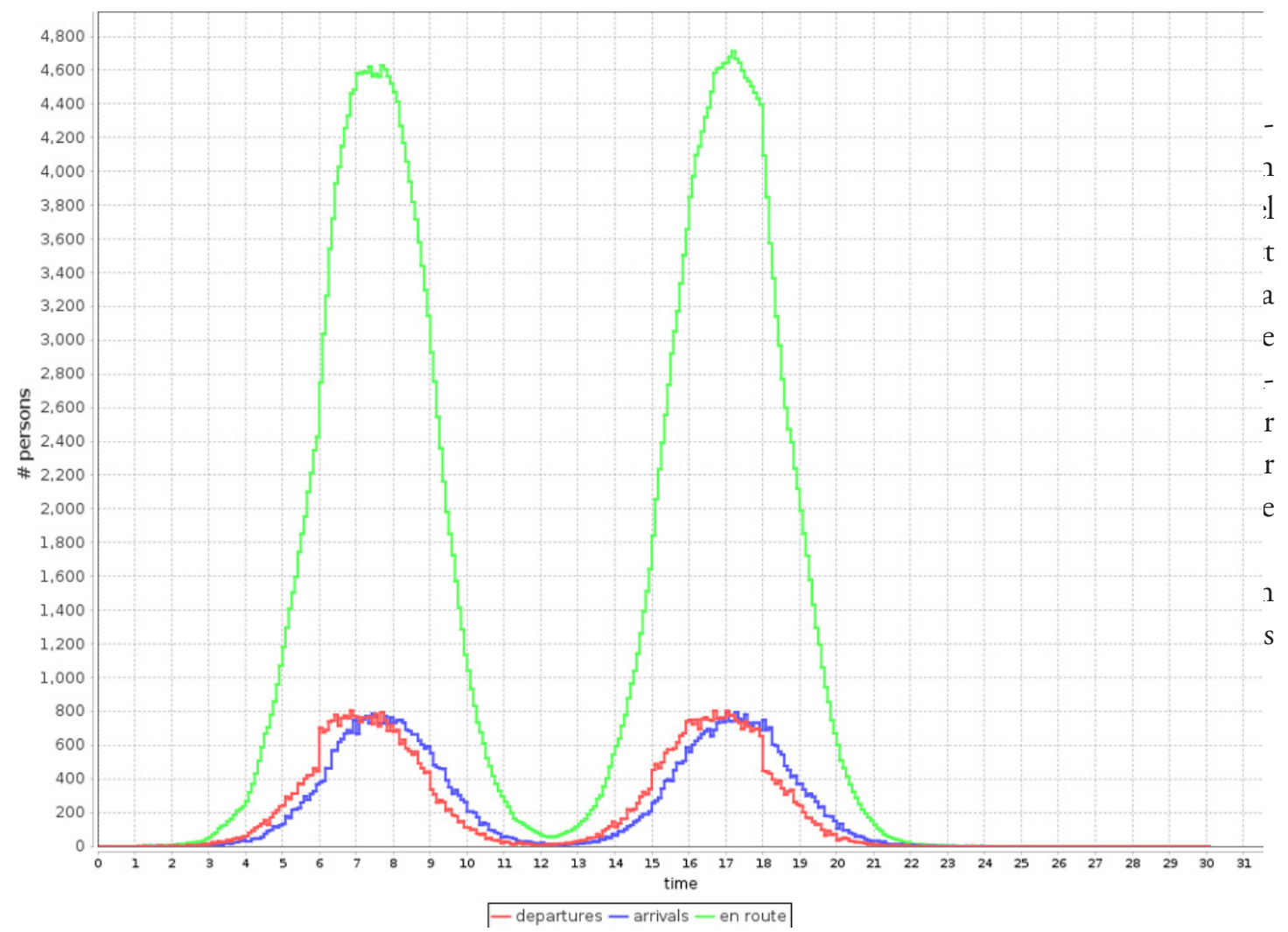

Figure 1. Example of work-trip departures, arrivals, and the corresponding number of persons en-route for the BAU model in 2013 (Horni et al., 2016) 


\section{$8 \quad$ Case study}

\subsection{SILO inputs and parameter calibration}

The Austin Metro region is 5,304 square miles and includes 2,102 traffic analysis zones (TAZs). In the base year of 2013, the model contains a population of 1,916,060, with 768,950 households, 810,751 dwellings, and 1,040,915 jobs. These counts were determined from a combination of PUMS data, which is aggregated to the PUMA-level, as well as data from the Austin metropolitan planning organization CAMPO, which has information at the TAZ level. A transportation network was created based on OSM data. Default values are used to set speeds, and only AV (car) traffic is considered at this point.

The most important input aside from the synthetic population is the available land for development at the TAZ level. CAMPO collects a detailed land-use inventory for the city of Austin and publishes this every year (Frank, 2019). The land that was categorized as "undeveloped" was determined to be land that was available to develop residentially. The database defines "undeveloped" as parcels without structures that have the potential for development. A GIS overlay of this categorized land was used to aggregate this information to determine the total developable land at the TAZ-level for the TAZs in the city of Austin. Unfortunately, there was not the same level of detailed data available for the non-city Austin Metro region. A linear regression model was used to make reasonable assumptions for available land in these non-city regions of Austin. Several iterations of linear regression models were run until only statistically significant $(\alpha=0.05)$ variables were left. See Table 2 (below) for these details.

Table 2. Linear regression model used to determine non-city developable land

\begin{tabular}{|l|c|c|c|c|}
\hline Variable & Coefficient & Std. Err. & t-stat & p-value \\
\hline Constant & $9.89 \times 10^{-2}$ & $8.34 \times 10^{-3}$ & 11.86 & 0.000 \\
\hline Population density (persons/acre) & $-5.88 \times 10^{-3}$ & $1.04 \times 10^{-3}$ & -5.66 & 0.000 \\
\hline Population density squared (persons/acre ${ }^{2}$ ) & $1.39 \times 10^{-4}$ & $3.50 \times 10^{-5}$ & 3.96 & 0.000 \\
\hline Employment density (jobs/acre) & $-1.25 \times 10^{-3}$ & $5.35 \times 10^{-4}$ & -2.33 & 0.020 \\
\hline Suburban (dummy = 1 if TAZ is suburban) & $3.55 \times 10^{-2}$ & $7.98 \times 10^{-3}$ & 4.44 & 0.000 \\
\hline Median income (dollars) & $-3.39 \times 10^{-7}$ & $8.25 \times 10^{-8}$ & -4.11 & 0.000 \\
\hline
\end{tabular}

While this is a defensible approach, it is easy to imagine how this may be biased and how it could underestimate the amount of available land in the non-city metropolitan regions. This is because noncity regions by definition are more rural, and so one would expect there to be more undeveloped land than in the city. Considering this fact, it is not terribly appropriate to train a linear regression model on data whose predictor variable takes certain values in one particular region and apply it to data whose predictor variable takes different values in another region. In this case, a linear regression model is trained on data with relatively less available land, and then applied to regions that one expects to have more available land. As such, the regression has some inherent bias.

Given these two motivations of (1) high parameter sensitivity and (2) concerns with using a linear regression model outside of its reasonable range, it is important to calibrate the available land values that are obtained for the non-city metropolitan regions. To perform this calibration, the model was run with varying percentages of the regression model results for these non-city Metropolitan regions. It was run with $50 \%, 75 \%, 100 \%, 125 \%, 150 \%, 175 \%, 200 \%, 250 \%$, and $300 \%$ of the available, developable land that was output from the linear regression model for the model base year of 2013. Then, available land is calibrated by comparing the household distribution in subsequent model years. In particular, the 
household distribution results for each of these model runs were compared to the household distribution from the CAMPO model in 2015, as well as for the CAMPO model household forecast for 2040.

To aggregate this calibration to a more digestible size, household distribution was compared at the county level for each model run to the CAMPO household distribution values in 2015 and 2040. As expected, decreasing the amount of available land in the non-city Metropolitan regions was further from the results in the CAMPO model, and increasing the amount of land in these regions helped, but only to a certain point. It was found that multiplying the developable land obtained from the linear regression model by $175 \%$ or 1.75 came the closest to the CAMPO model in 2015 and 2040 . As such, these values for available and developable land were used in all scenarios discussed.

Several other important parameters were calibrated relative to the Maryland implementation of SILO. This includes parameters on pricing and construction demand, which proved to be the next most sensitive parameters for our modeling. The pricing model in SILO's real estate model updates dwelling costs based on vacancy rates, which is taken as a proxy for demand. This is done for each dwelling type in each TAZ. Structural vacancy rates are defined as the regionwide vacancy rate for each dwelling type. If vacancy rates in a given TAZ are lower than the structural vacancy rate, dwelling prices increase, and if they are higher, prices decrease. However, dwelling price increases happen faster than decreases, reflecting the landlord's desire to keep prices as high as possible (Moeckel, 2018a). Structural dwelling vacancy rates are based on the vacancy rates in the base year and are as follows: $3 \%$ for single family detached, $5.5 \%$ for single family attached, $5.5 \%$ for multi-family with two to four dwellings, $7 \%$ for multi-family with five or more dwellings, and $6.5 \%$ for mobile homes.

The median home price in Austin has risen 62\% over the past eight years and $40 \%$ over the past five years, so a maximum change of two percent year over year as was used in the Maryland implementation would not replicate true housing prices for the area (Novak, 2019). Because of this, a maximum pricing change of $10 \%$ was allowed in the model to reflect major year over year pricing changes in more desirable areas of Austin.

Similarly, because of the near-doubling in population Austin is expecting to see over the course of the model years, the construction demand parameters needed to be adjusted to keep up with this population growth. Figure 2 shows the construction demand as a function of vacancy rate for the different dwelling types modeled in SILO. This was calibrated based on the number of housing units of each type that have been built in Austin over the past ten years. Multi-family dwellings with greater than five dwellings per building have been constructed most often, followed by single family detached. These two types dominate the market, with much fewer of the other three dwelling types being constructed (City of Austin, 2019). 


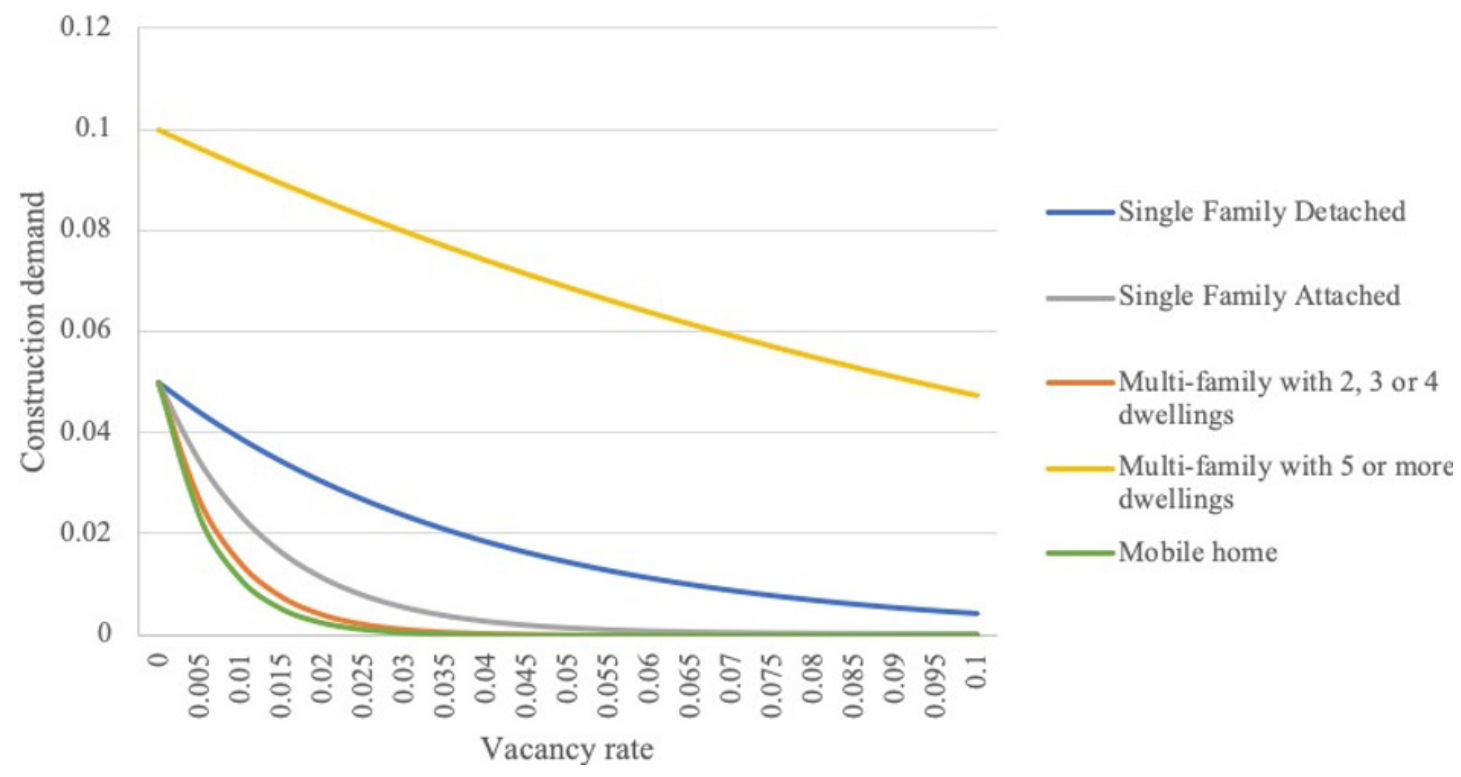

Figure 2. Construction demand for dwelling types as a function of vacancy rate

While key parameters were calibrated so that the model reasonably represented the Austin Metro region, many parameters were left over from the Maryland application. For example, all of the demographic parameters were left the same as they were in the Maryland implementation. The demographic events did not need to be re-calibrated because of time constraints as well as the limited importance of those parameters for the scope of this project. This means that the probability of giving birth, getting married, death, etc., were not calibrated to Austin-specific data. They were calibrated for Maryland, and those values were used here. The authors believe that the demographic results are still reasonable for Austin because of the similarity of the study areas.

\section{$9 \quad$ Scenario descriptions}

Four main scenarios are defined and analyzed over a 27-year period. First is a business-as-usual (BAU) $0 \% \mathrm{AV}$ scenario where the traditional passenger car is the main travel mode and work-trip travel time is a major driver in household location and relocation decision making. The second case, the "AV $-50 \%$ VTTS reduction" scenario, looks at a scenario where personal AVs are used across the network. To model this simply, SILO was updated so that households value their work-trip travel time at half the amount they do in the BAU scenario, with respect to their household location and relocation decision making. This means that, when households are evaluating their satisfaction with their current dwelling, or when households are moving and considering new dwellings, the workers' work-trip travel time factors into the decision-making at a 50\% lower priority than it did in the BAU scenario. This second scenario is meant to represent an upper bound of the changes in the value of travel time that are expected when self-driving vehicle technologies emerge assuming workers travel privately by AVs, and can work, sleep, or do some other task of value while commuting. The third scenario is the "AV - 25\% VTTS reduction" scenario. This is the same as the "AV - 50\% VTTS reduction" scenario, but the workers' work-trip travel time factors into the decision-making at a $25 \%$ lower priority than it did in the BAU scenario. This third scenario is meant to represent a lower bound of the changes in the value of travel time that are expected when self-driving vehicle technologies emerge. Note that vehicle occupancy is unaltered 
in both of these AV scenarios. The reason for these two different VTTS reduction scenarios is because there is a lot of uncertainty as to how much $A V s$ will impact travelers' commuting trips. It was recently estimated that AVs could reduce work-trip VTTS by $31 \%$ compared to traditional driving, and so $25 \%$ and $50 \%$ were deemed good reductions to consider (Steck, Kolarova, Bahamonde-Birke, Trommer, \& Lenz, 2018). Finally, the fourth case looks at the case of shared AV (SAV) implementation with a high penetration of dynamic ride sharing (DRS). This scenario is called the "Hi-DRS SAV" scenario from here forward. This is modeled in a simplified fashion by updating SILO so that households value their work-trip travel time at $25 \%$ the level they do in the BAU scenario, with respect to their household location and relocation decision making. In addition, MATSim is updated in this scenario to have twice the capacity. This is meant to model a situation where there are about $50 \%$ fewer vehicles on the road, meaning the average vehicle occupancy is about two, which is double the average vehicle occupancy assumed in the first two scenarios.

Note that the model years are based on predictions for 2013 - 2040, but because we are looking at scenarios with full penetration of $A V s$, we do not assume those to be representative years for the full implementation of this technology. However, this is the data that we had available, so these years were used. But the results might best be considered from years 2033 - 2060, for example, when this technology may be heavily or fully adopted for the whole duration.

\section{Results}

Table 3 below gives a summary of some major results that can be drawn from the four scenarios that are run from the base to the final model year in SILO, with MATSim running every ten model years to update work-trip travel times. The first factor to note from Table 3 is that the Austin Metro region is growing dramatically over the model time period. More than a million households are expected to move to the region in the 27 years between the base and final model year, which is a $134 \%$ increase in the total number of households. On this note, it is also relevant to realize that the number of persons is fixed and exogenous to the model. This means that variations in household counts in the different scenarios are due to slight changes in household compositions which are modeled stochastically. Another major result of note in this realm is that many more of these households live in the city of Austin in the BAU scenario than in the either of the AV scenarios or the Hi-DRS SAV scenarios, meaning that there are many fewer households living in the non-City Metropolitan region in the BAU scenario than there are in the AV scenarios or the Hi-DRS SAV scenario.

There are also more single-family dwellings in the AV scenarios and the Hi-DRS SAV scenario as compared to the BAU scenario in the final model year. This is because there is a higher preference for this dwelling type due to lower travel costs in these AV and SAV scenarios relative to the BAU scenario $(0 \% \mathrm{AV})$, so there is more demand for, and thus more construction of, single-family dwellings. Similarly, there are more multi-family dwellings with five or more dwellings in them in all scenarios because there are more of these dwellings constructed (see Figure 2). New dwellings have the highest quality, and since this is more valued on a relative basis in the AV - 50\% VTTS reduction scenario relative to the BAU scenario, more people move into these MF5+ dwellings, and thus there is higher demand, and more are constructed. 
Table 3. Summary of scenario results comparing model base year (2013) to end year (2040)

\begin{tabular}{|c|c|c|c|c|c|}
\hline & Base year & $\begin{array}{c}\text { BAU }(0 \% \text { AV }) \\
\text { - end year }\end{array}$ & $\begin{array}{c}\text { AV (50\% } \\
\text { VTTS reduc- } \\
\text { tion) - end } \\
\text { year }\end{array}$ & $\begin{array}{c}\text { AV (25\% } \\
\text { VTTS reduc- } \\
\text { tion) - end } \\
\text { year }\end{array}$ & $\begin{array}{c}\text { Hi-DRS SAV } \\
\text { scenario-end } \\
\text { year }\end{array}$ \\
\hline \multicolumn{6}{|c|}{ Household-Level Statistics } \\
\hline Number of households & 768,950 & $1,798,924$ & $1,798,648$ & $1,798,750$ & $1,799,542$ \\
\hline $\begin{array}{l}\text { Number of households in } \\
\text { the city of Austin (CoA) }\end{array}$ & 462,465 & 944,520 & 894,744 & 915,153 & 892,711 \\
\hline $\begin{array}{l}\text { Number of households in } \\
\text { non-CoA Metro area }\end{array}$ & 306,485 & 854,404 & 903,904 & 883,597 & 907,182 \\
\hline \multicolumn{6}{|c|}{ Dwelling-Level Statistics } \\
\hline Number of SFD dwellings & 489,673 & 863,756 & 921,076 & 851,884 & 921,947 \\
\hline Number of SFA dwellings & 30,497 & 32,880 & 33,507 & 32,832 & 33,638 \\
\hline Number of MF5+ dwellings & 206,120 & 837,169 & 820,462 & 826,955 & 824,533 \\
\hline $\begin{array}{l}\text { Number of MF2-4 dwell- } \\
\text { ings }\end{array}$ & 45,744 & 52,245 & 51,760 & 53,831 & 51,983 \\
\hline Number of MH dwellings & 38,927 & 48,559 & 52,516 & 49,762 & 53,227 \\
\hline \multicolumn{6}{|c|}{ Available, Developable Land } \\
\hline $\begin{array}{l}\text { Total available, developable } \\
\text { land }\end{array}$ & $426.9 \mathrm{mi}^{2}$ & 245.2 & 222.9 & 235.3 & 227.4 \\
\hline $\begin{array}{l}\text { Available, developable land } \\
\text { in the CoA }\end{array}$ & $69.0 \mathrm{mi}^{2}$ & 8.9 & 10.6 & 9.7 & 14.5 \\
\hline $\begin{array}{l}\text { Available, developable land } \\
\text { in metro areas }\end{array}$ & $358.0 \mathrm{mi}^{2}$ & 236.3 & 212.3 & 225.6 & 212.9 \\
\hline \multicolumn{6}{|c|}{ Work-Trip Statistics } \\
\hline $\begin{array}{l}\text { Average work-trip travel } \\
\text { time }\end{array}$ & $31.4 \mathrm{mins}$ & 38.5 & 41.6 & 38.9 & 39.8 \\
\hline $\begin{array}{l}\text { Average work-trip time for } \\
\text { those living in the } \mathrm{CoA}\end{array}$ & $22.3 \mathrm{mins}$ & 25.7 & 25.6 & 25.7 & 25.6 \\
\hline $\begin{array}{l}\text { Avg. work-trip time for } \\
\text { those living in metro areas }\end{array}$ & $41.4 \mathrm{mins}$ & 48.4 & 52.1 & 49.9 & 50.5 \\
\hline $\begin{array}{l}\text { Number of commuters with } \\
60+\text { minute work-trips }\end{array}$ & 2639 & 6006 & 8007 & 6420 & 6993 \\
\hline
\end{tabular}

There is a $42.6 \%$ reduction in available developable land in the 27 -year period between the base to final model year in the BAU scenario $(0 \% \mathrm{AV})$, a $47.8 \%$ reduction in the same period in the AV $50 \%$ VTTS reduction scenario, a $44.9 \%$ reduction in the AV - 25\% VTTS reduction scenario, and a $46.7 \%$ reduction in the Hi-DRS SAV scenario. There is a larger total reduction in the AV scenarios and the Hi-DRS SAV scenario than in the BAU scenario because households care relatively more about size than they do in the BAU scenario, so there are more SFDs which are on larger plots of land. There is also a larger reduction in available land in the CoA in the BAU scenario than there is in the AV and the Hi-DRS SAV scenarios. On a related note, there are more households living in the CoA in the BAU scenario than there are in the other scenarios, and less living in the metro regions in the BAU scenario than in the other scenarios.

Finally, work-trip travel times increase significantly in all four scenarios in the 27 -year period be- 
tween the base and final model year. However, they increase significantly more on average in the HiDRS SAV scenario, and even more so in the AV - 50\% VTTS reduction scenario, by the final model year as compared to the BAU scenario $(0 \% \mathrm{AV})$ in the final model year, on average. The AV $-25 \%$ VTTS reduction had the smallest increase in average work-trip travel time relative to the BAU scenario. Additionally, there are many more people with extreme work-trips of over one hour in the AV scenarios and the Hi-DRS SAV scenario in the final model year, compared to the BAU scenario in the final model year.

For ease of understanding, as the discussion of results goes into more detail in subsequent sections, the AV - 25\% VTTS reduction is dropped from the conversation and the AV - 50\% VTTS reduction scenario is simply referred to as the " $100 \% \mathrm{AV}$ " scenario.

\subsection{Work-trip travel time results}

Now, work-trip travel time results are compared across the four scenarios. Figure 3 shows the distribution of work-trip travel times across all workers living and working in the Austin Metro region in the base model year and 20 years after the base year in each scenario. The base year is shown in orange in Figure 3, and the average work-trip travel time in the base year is 31.4 minutes.

The BAU scenario 20 years after the base year is shown in green in Figure 3. In this scenario, each bin seems pretty uniformly stretched upwards, so the distribution looks similar but there are more travelers in each bin. The average work-trip travel time 20 years after the base year in the BAU scenario is 38.5 minutes, so work-trip times are nearly five minutes longer across all workers, relative to the base model year.

The $100 \%$ AV scenario 20 years after the base year is shown in yellow in Figure 3. The major distinction of note in this figure is how many more workers are commuting sixty minutes or more to work. This makes sense because households are no longer considering this work-trip time as strongly in their household location and relocation decisions, making other dwelling attributes such as dwelling size and quality more important. The average work-trip travel time 20 years after the base year in the $100 \% \mathrm{AV}$ scenario is 41.6 minutes, so work-trip times are over ten minutes longer across all workers, relative to the base model year.

The Hi-DRS SAV scenario 20 years after the base year is shown in blue in Figure 3. The main difference between the $100 \%$ AV and the Hi-DRS SAV scenario is that there is a $12.7 \%$ decrease in the number of extreme work-trips of 60 minutes or more one-way. The average work-trip travel time 20 years after the base year in the Hi-DRS SAV scenario is 39.8 minutes, so work-trip times are over eight minutes longer across all workers, relative to the base model year. 


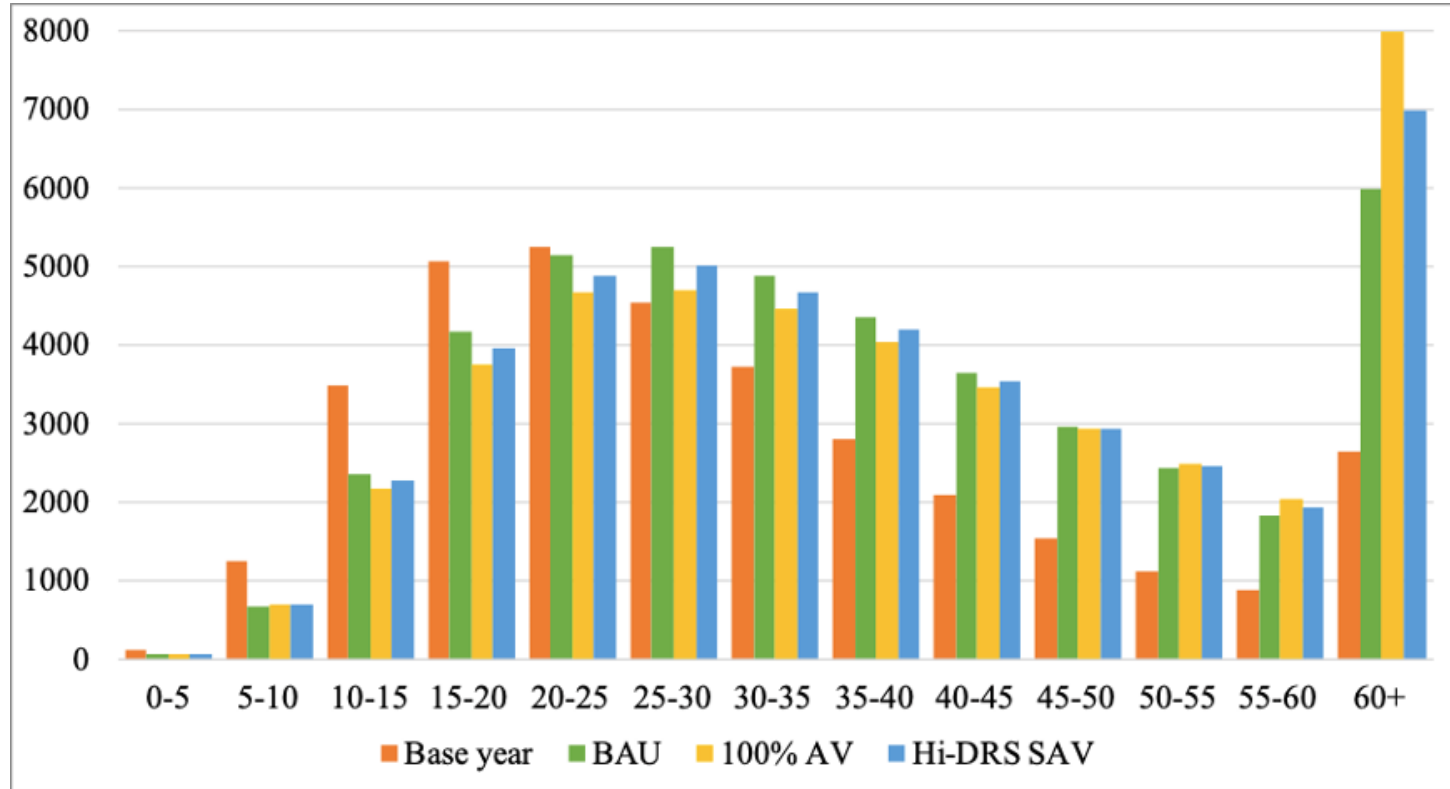

Figure 3. Work-trip travel times in the Austin metro in the base model year and 20 years after the base year in each scenario

\section{Household location results}

The total number of households in the region increases by $134 \%$ in both scenarios. This is a major growth from about 769,000 households in the BAU model year to 1.80 million households in the final model year. In the $100 \% \mathrm{AV}$ scenario, more of this growth is happening in the less-central non-city metropolitan regions than the BAU scenario $(0 \% \mathrm{AV})$. The number of households in the non-city metro regions in the $100 \%$ AV scenario grows by $194.9 \%$ from the base to the final model year, compared to the BAU scenario which grows by $178.8 \%$ in the same area over the same time period. Similarly, there is then less growth happening in the city of Austin in the 100\% AV scenario than in the BAU scenario. In the $100 \% \mathrm{AV}$ scenario, the number of households in the city of Austin grows by $93.5 \%$ from the base to the final model year, compared to the BAU scenario which grows by $104.2 \%$ in the same area over the same time period. Figure 4 below shows the spatial layout of the difference in the number of households by zone in the final model year of the $100 \% \mathrm{AV}$ scenario relative to the final model year of the BAU scenario $(0 \% \mathrm{AV})$. Positive values in the figure (shown in dark orange) indicate more households in that zone in the $100 \% \mathrm{AV}$ scenario relative to the BAU scenario in the final model year. Negative values in the figure (shown in white) indicate fewer households in that zone in the $100 \% \mathrm{AV}$ scenario relative to the BAU scenario in the final model year. 


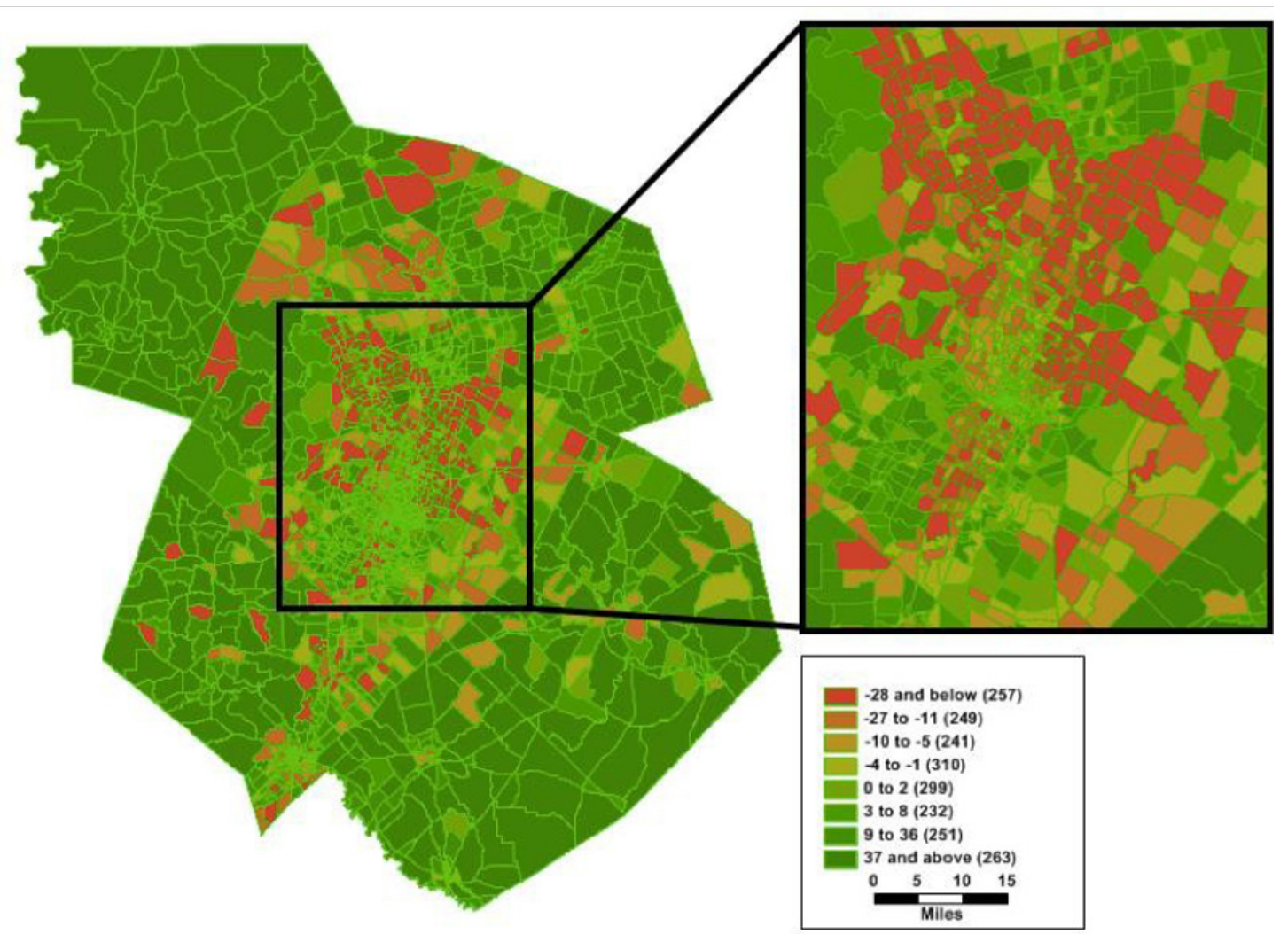

Figure 4. Difference in where households are located in the 100\% AV scenario relative to the BAU scenario in the final model year

In the Hi-DRS SAV scenario, more of this growth is happening in the non-city metropolitan regions than the BAU scenario ( $0 \% \mathrm{AV})$. There is also slightly more growth happening in the non-city metropolitan regions in the Hi-DRS SAV scenario relative to the $100 \%$ AV scenario. In the Hi-DRS SAV scenario, the number of households in the non-city metro regions grows by $196.0 \%$ from the base to the final model year, compared to the BAU scenario which grows by $178.8 \%$ in the same area over the same time period. Similarly, there is then less growth happening in the city of Austin in the Hi-DRS SAV scenario than in the BAU scenario. In the Hi-DRS SAV scenario, the number of households in the city of Austin grows by $93.0 \%$ from the base to the final model year, compared to the BAU scenario which grows by $104.2 \%$ in the same area over the same time period. A figure is not shown for this scenario, because it looks quite similar at the spatial level.

\subsection{Available and developable land results}

Austin-Round Rock, Texas, is number four on the list of the fastest growing cities in America according to USA Today (2019). Because of this, it is expected that available and developable land will decrease significantly over the model period of the base to the final model year. This is seen through a $42.6 \%$ reduction in developable land over the model time period in the BAU scenario ( $0 \% \mathrm{AV})$, a $47.8 \%$ reduction in the $100 \%$ AV scenario, and a $46.7 \%$ reduction in the Hi-DRS SAV scenario. This larger reduction in developable land in the $100 \% \mathrm{AV}$ and in the Hi-DRS SAV scenarios compared to the BAU scenario is because households care relatively more about size than they do in the BAU scenario, so there are more single-family dwellings constructed, which take up more land. 
There is also a larger reduction in available land in the city of Austin in the BAU scenario $(0 \% \mathrm{AV})$ than there is in the city in the $100 \% \mathrm{AV}$ and in the Hi-DRS SAV scenarios. This is because households are more willing to live in the less central regions and less willing to pay higher prices to live in the city in both of the AV scenarios, because they do not care as much about their work-trip travel distance. In the BAU scenario, there is an $87.1 \%$ reduction in available land in the city and a $34.0 \%$ reduction in available land in the non-city metropolitan regions. In the $100 \%$ AV scenario, there is an $84.7 \%$ reduction in available land in the city and a $40.7 \%$ reduction in available land in the non-city metropolitan regions. In the Hi-DRS SAV scenario, there is an $78.9 \%$ reduction in available land in the city and a $40.5 \%$ reduction in available land in the non-city metropolitan regions. Figure 5 below indicates the spatial distribution of available land by zone in the final model year in the $100 \% \mathrm{AV}$ scenario relative to the BAU scenario. Positive values in the figure (shown in dark green) indicate more available land in that zone in the respective AV scenario relative to the BAU scenario in the final model year. Negative values in the figure (shown in white) indicate less available land in that zone in the $100 \% \mathrm{AV}$ scenario relative to the BAU scenario in the final model year. A figure is not shown for the Hi-DRS SAV scenario, because it looks quite similar at the spatial level.

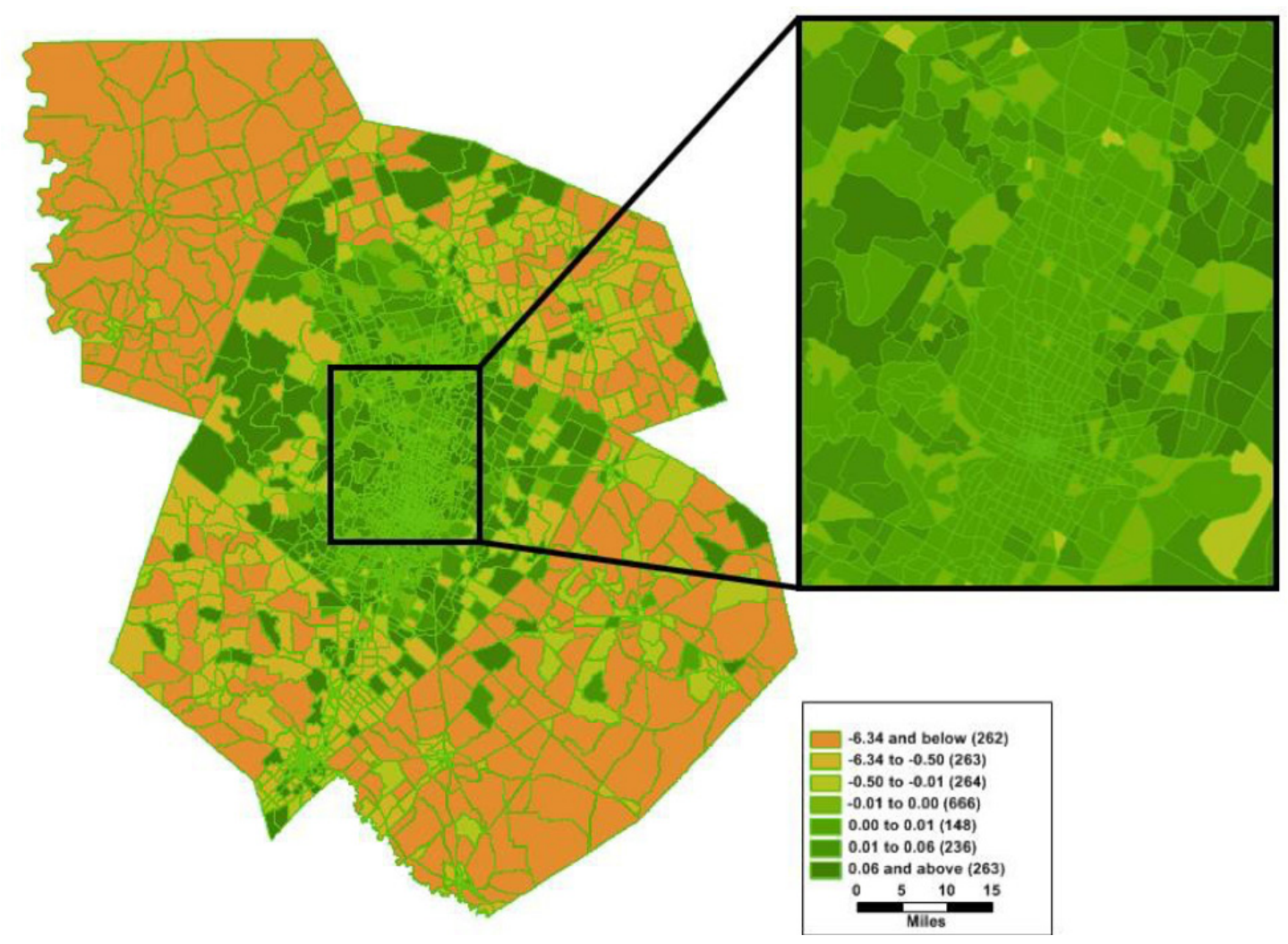

Figure 5. Difference in the amount of available, developable land in the $100 \%$ AV scenario relative to the BAU scenario in the final model year 


\section{Conclusions and limitations}

The adoption of $\mathrm{AVs}$ is fast approaching as many companies are hard at work on their version of the technology. As such, engineers and planners must begin to plan and prepare for important impacts of their adoption. There are many benefits one could imagine from the advent of AVs, including safety improvements, increased economic productivity, and improved quality of life. However, there are also secondary negative impacts of these technological changes that are plausible if appropriate action is not taken to mitigate them. This includes the impacts of urban sprawl as are discussed in the present study, which has negative consequences including increased emissions and congestion. There are many other negative impacts one could envision of AV technology adoption that are not the focus of this study but require future work. This includes induced demand for travel, issues with equity surrounding the technology, and safety and privacy issues. There are many opportunities for important research in the area of AV impacts.

The present study provides an initial look at potential residential land-use implications from a reduction in the value of the time it takes to complete one's work-trip which will be expected in a future of fully automated vehicles. Because this model is not fully calibrated for the model region, one should really only consider the relative differences between the BAU scenario and the two AV scenario results, rather than the true values, and make conclusions based on those.

Of major note, it was seen that work-trip travel times increase quite significantly in the $100 \% \mathrm{AV}$ scenario relative to the BAU scenario $(0 \% \mathrm{AV}) 20$ years after the base year. There was also an increase in work-trip travel times in the Hi-DRS SAV scenario relative to the BAU scenario 20 years after the base year, to a lesser degree. Specifically, average work-trip travel times increase by 3.1 minutes in the $100 \%$ $\mathrm{AV}$ scenario relative to the BAU scenario $(0 \% \mathrm{AV})$ in the final model year, which is an $8.1 \%$ increase. Additionally, average work-trip travel times increase by 1.3 minutes in the Hi-DRS SAV scenario relative to the BAU scenario in the final model year, which is a $3.4 \%$ increase. There is also an increase in the number of "extreme" work-trip of 60 minutes or more. There are 2,001 more workers in the model region with an extreme work-trip in the $100 \%$ AV scenario relative to the BAU scenario in the final model year, which is a 33.3\% increase. There are also 987 more workers in the model region with an extreme work-trip in the $100 \%$ AV scenario relative to the BAU scenario in the final model year, which is a $16.4 \%$ increase.

The work in this study also found differences in the distribution of households across the model region between the two AV scenarios relative to the BAU scenario as well. There were 49,776 fewer households in the city of Austin in the 100\% AV scenario relative to the BAU scenario ( $0 \%$ AV) in the final model year, which is a 5.3\% decrease. Similarly, there were 51,809 fewer households in the city of Austin in the Hi-DRS SAV scenario relative to the BAU in the final model year, which is a $5.5 \%$ decrease. On this same note, there were 49,500 more households that were located in the non-city metropolitan regions of Austin Metro in the $100 \%$ AV scenario relative to the BAU scenario in the final model year, which is a 5.8\% decrease. Similarly, there were 52,778 more households that were located in the non-city metropolitan regions of Austin Metro in the Hi-DRS SAV scenario relative to the BAU scenario in the final model year, which is a $6.2 \%$ decrease.

Also related to these results are the differences in available and developable land. There is relatively more available land in the city of Austin in the 100\% AV and the Hi-DRS SAV scenarios relative to the BAU scenario in the final model year and relatively less available land in the city of Austin in the $100 \%$ AV and the Hi-DRS SAV scenarios relative to the BAU scenario in the final model year. Namely, there was 24.0 square miles less land located in the non-city metropolitan regions of Austin Metro in the $100 \%$ AV scenario relative to the BAU scenario $(0 \% \mathrm{AV})$ in the final model year, which is a $10.2 \%$ 
decrease. Additionally, there was 23.4 square miles less land located in the non-city metropolitan regions of Austin Metro in the Hi-DRS SAV scenario relative to the BAU scenario in the final model year, which is a $9.9 \%$ decrease. Along the same lines, there was 1.7 square miles more land located in the city of Austin in the $100 \%$ AV scenario relative to the BAU scenario in the final model year, which is a $19.1 \%$ increase. Additionally, there was 5.6 square miles more land located in the city of Austin in the Hi-DRS SAV scenario relative to the BAU scenario in the final model year, which is a $62.9 \%$ increase. All of these are directionally what one would expect when $A V s$ and $S A V$ s are deployed and work-trip times are not as strong of a consideration in household location and relocation decision-making.

It is interesting that work-trip travel times do not increase as dramatically in the Hi-DRS SAV scenario as they do in the $100 \% \mathrm{AV}$ scenario relative to the BAU scenario, but the land-use impacts are similar and even more pronounced in the Hi-DRS SAV scenario than they are in the $100 \%$ AV scenario. This makes sense because sharing rides in the SAV scenario leads to shorter travel times because of the reduction in the number of vehicles on the road relative to the AV scenario. Because these travel times decrease, households are willing to live longer distances from their workplaces, increasing urban sprawl. Of particular note, although the sprawl is more significant in the Hi-DRS SAV scenario, the emissions implications would be lower than the $100 \% \mathrm{AV}$ scenario because the rides are shared, meaning there are fewer vehicles traveling those longer distances.

These differences between scenarios in available and developable land, the composition of singlefamily vs. multi-family dwellings, and so on, are precisely the reasons we run these more complicated microsimulation ITLUMs. In using this SILO-MATSim integration, we are able to simulate interactions that do not appear in more simplified models of AV adoption. This is to note that just running a mode choice model, for example, would not give us the full picture and would not be able to capture some of these secondary impacts of a major mobility shift such as the implementation of AVs.

It is also important to understand some of the limitations to our study. For one, there are major simplifications made in the scenario definitions for the "100\% AV" and the "Hi-DRS SAV" scenarios, so these results must be considered taking into account these simplifications. In addition, AVs, and particularly SAVs, have major implications for parking needs. Currently, parking is an important housing choice consideration, and if you do not need to worry about parking because you can easily use SAVs on-demand, this could cause conflicting results to our study, such as re-urbanization. These factors are not considered. In addition, telework is becoming a more common trend in workplaces, and is unfortunately not represented by SILO as an option for workers. An additional limitation of note, SILO does not account for any new travelers that may occur in response to the introduction of AV technology, such as those currently without driver's licenses. There are other parallel technological advancements that could also stimulate AV technology or alter our mobility patters, such as virtual reality and $5 \mathrm{G}$ communication technologies. These types of developments are not considered in this study. Finally, there are limitations in assumptions made in the SILO model framework such as the fact that the only transportation consideration in the household location and relocation decision-making is the work-trip travel time. This is a major limitation because the trip to and from work only accounts for $17 \%$ of the total average annual person miles traveled per household (U.S. DOT, 2018).

This is a crude initial look at some of the residential land-use and transportation impacts that could occur in a future of self-driving vehicles. Further research is needed in this area. It would be beneficial future work to increase the complexity of the integration of the land-use and transportation model. This could include using AV and/or SAV MATSim plug-ins to both generate AV/SAV travel demand and to simulate all of the traffic in the system, not just work-trips. Then, one could also model a mix of AVs and traditional passenger cars. It would of course be beneficial to spend the time to fully calibrate the LUM for the model region too. Though this is very time-consuming, it would improve the reasonability of 
results. Finally, it would be constructive to increase the complexity of the LUM to include more accessibility and transportation characteristics into the household location and relocation decision-making. For example, many households care about the distance to the nearest grocery store and proximity to restaurants and retail, not just their work-trip distance. As more complexity is added to these ITLUMs, there is of course further calibration and data needs. However, this is where the field of ITLUMs should be headed. 


\section{References}

City of Austin. (2019). New residential units summary by calendar year and building type. Retrieved from https://data.austintexas.gov/Building-and-Development/New-Residential-Units-Summaryby-Calendar-Year-and/2y79-8diw

Cohen, T., \& Cavoli, C. (2019). Automated vehicles: Exploring possible consequences of government (non)intervention for congestion and accessibility. Transport Reviews, 39(1), 129-151.

Department of Numbers. (2017). Austin, Texas, residential rent and rental statistic. Retrieved from https://www.deptofnumbers.com/rent/texas/austin/\#vacancy_rate

Dowling, R., \& Morgan, A. (2019). Foreseeing the impact of transformational technologies on land use and transportation. Washington, DC: National Academy of Sciences.

Edmonds, E. (2017). AAA reveals true cost of vehicle ownership. Retrieved from https://newsroom.aaa. com/tag/driving-cost-per-mile/

Frank, P. (2019). City of Austin land-use inventory detailed. Retrieved from https://data.austintexas. gov/Locations-and-Maps/Land-Use-Inventory-Detailed/f9m-h5qy

Hawkins, J., \& Habib, K. (2018). Integrated models of land use and transportation for the autonomous vehicle revolution. Transport Reviews, 39(1), 66-83.

Horni, A., Nagel, K., \& Axhausen, K. W. (2016). The multi-agent transport simulation MATSim. London: Ubiquity Press.

Huang, Y., Kockelman, K., \& Quarles, N. (2019). How will self-driving vehicles affect U.S. megaregion traffic? The case of the Texas triangle. Paper presented at the 98th Annual Meeting of the Transportation Research Board, Washington, D.C., and submitted for publication in Journal of Transport Geography.

Moeckel, R. (2019a). SILO Model Java Code, GitHub. Retrieved from https://github.com/msmobility/silo/

Moeckel, R. (2018a). Simple integrated land-use orchestrator. Retrieved from silo.zone

Moeckel, R. (2018b). NCHRP synthesis 520: Integrated transportation and land use models: A synthesis of highway practice. Washington, DC: National Academy of Sciences.

Moeckel, R. (2015). Modeling constraints versus modeling utility maximization: Improving policy sensitivity for integrated land-useltransportation models. Proceedings of the 94th Annual Meeting of the Transportation Research Board, January 11-15, Washington, DC.

Muller, P. (2017). Transportation and urban form: Stages in the spatial evolution of the American metropolis. In S. Hanson \& G. Giuliano (Eds.), The geography of urban transportation (pp. 57- 85). New York: Guilford Press.

National Conference of State Legislatures. (2019). Autonomous vehicles: Self-driving vehicles enacted legislation. Retrieved from http://www.ncsl.org/research/transportation/autonomous-vehicles-selfdriving-vehicles-enacted-legislation.aspx

Novak, S. (2019, January 22). 2018 another record year for Austin-area housing market, Statesman. Retrieved from https:/www.statesman.com/news/20190122/2018-another-record-year-for-austinarea-housing-market

Open Street Maps. (2019). Retrieved from https://www.openstreetmap.org/\#map=9/30.3752/-98.3194

Quarles, N., \& Kockelman K. (2019). Americans' plans for acquiring and using electric, shared and selfdriving vehicles. Under review for publication in Research in Transportation Economics.

SAE International. (2018, December 11). SAE international releases updated visual chart for its Levels of driving automation standard for self-driving vehicles. Retrieved from https:/www.sae.org/news/ press-room/2018/12/sae-international-releases-updated-visual-chart-for-its- $\% \mathrm{E} 2 \% 80 \% 9$ Clevelsof-driving-automation $\% \mathrm{E} 2 \% 80 \% 9 \mathrm{D}$-standard-for-self-driving-vehicles 
Simoni, M. D., Kockelman, K. M., Gurumurthy, K. M., \& Bischoff, J. (2018). Congestion pricing in a world of self-driving vehicles: An analysis of different strategies in alternative future scenarios. Transportation Research Part C: Emerging Technologies 98, 167-185. Retrieved from http://www.caee. utexas.edu/prof/kockelman/public_html/TRB19CBCP_with_AVs.pdf

Soteropoulos, A., Berger, M., \& Ciari, F. (2019). Impacts of automated vehicles on travel behavior and land use: An international review of modelling studies. Transport Reviews, 39(1), 29-49.

Steck, F., Kolarova, V., Bahamonde-Birke, F., Trommer, S., \& Lenz, S. (2018). How autonomous driving may affect the value of travel time savings for commuting. Transportation Research Record, 2672(46), 11-20.

United States Census Bureau. (2018). American Community Survey 2017 ACS 1-year PUMS. Retrieved from https://www.census.gov/programs-surveys/acs/data/pums.html

United States Census Bureau. (2017). American fact finder mean travel time to work of workers 16 years and over who did not work at home. Retrieved from https://factfinder.census.gov/faces/tableservices/jsf/pages/productview.xhtml?src=bkmk

United States Department of Labor. (2019). Bureau of Labor Statistics consumer expenditure surveys. Retrieved from https://www.bls.gov/cex/tables.htm

United States Department of Transportation. (2018). Summary of travel trends: 2017 National Household Travel Survey. Retrieved from https://nhts.ornl.gov/assets/2017_nhts_summary_travel_trends. pdf

USA Today. (2019, May 9). America's fastest growing cities. Retrieved from https:/www.usatoday.com/ picture-gallery/money/2019/05/03/americas-fastest-growing-cities/39442563/

Ziemke, D., Nagel, K., \& Moeckel, R. (2016). Towards an agent-based, integrated land-use transport modeling system. Procedia Computer Science, 83, 958-963. 